\title{
Parameter Extraction of PV Module using NLS Algorithm with Experimental Validation
}

\author{
Alivarani Mohapatra', Byamakesh Nayak $^{2}$, K. B. Mohanty ${ }^{3}$ \\ ${ }^{1,2}$ School of Electrical Engineering, KIIT University, Bhubaneswar, India \\ ${ }^{3}$ Dept. of Electrical Engineering, NIT Rourkela, Rourkela, India
}

\begin{tabular}{l} 
Article Info \\
\hline Article history: \\
Received Dec 9, 2016 \\
Revised Mar 27, 2017 \\
Accepted May 11, 2017 \\
\hline
\end{tabular}

\section{Keywords:}

Electrical characteristic Maximum power point (MPP) Nonlinear least square method Parameter extraction Polycrystalline ELDORA-40 PV panel

\begin{abstract}
Photovoltaic (PV) module parameters act an important task in PV system design and simulation. Most popularly used single diode Rsh model has five unknown electrical parameters such as series resistance (Rse), shunt resistance (Rsh), diode quality factor (a), photo-generated current (Ipg) and dark saturation current (Is) in the mathematical model of PV module. The PV module output voltage and current relationship is represented by a transcendental equation and is not possible to solve analytically. This paper proposes nonlinear least square (NLS) technique to extract five unknown parameters. The proposed technique is compared with other two popular techniques available in the literature such as Villalva's comprehensive technique and modified Newton-Raphson (N-R) technique. Only two parameters Rse and Rsh are estimated by Villalva's technique, but all single diode unknown electrical parameters can be estimated by the NLS technique. The accuracy of different estimation techniques is compared in terms of absolute percentage errors at MPP and is found the minimum for the proposed technique. The elapsed time for parameter estimation for NLS technique is minimum and much less compared to other two techniques. Extracted parameters of polycrystalline ELDORA-40 PV panel by the proposed technique have been validated through simulation and experimental current-voltage $(\mathrm{I}-\mathrm{V})$ and power-voltage $(\mathrm{P}-\mathrm{V})$ characteristics.
\end{abstract}

Copyright $@ 2017$ Institute of Advanced Engineering and Science. All rights reserved.

\section{Corresponding Author:}

Alivarani Mohapatra

School of Electrical Engineering

KIIT University, Bhubaneswar-24

Odisha, India

Email: aliva.priti@gmail.com

\section{INTRODUCTION}

Solar photovoltaic (PV) energy is becoming popular day by day, and a good deal of research is going on PV generation because it needs less maintenance, simple to model and gives clean energy [1], [2]. The basic unit of a PV system is the PV cell which converts light energy into electrical energy. To meet the load demand, many PV cells are joined in series and parallel fashion to make PV modules or panels [3]. For large power application, many panels are again linked up in series-parallel fashion to make PV array. Performance and efficiency of PV system are still below expectation, so a large amount of study is going on to enhance the efficiency of the PV system. For extracting maximum power from the PV panel, the load line must pass through the maximum power point (MPP). A converter with a proper MPP tracking (MPPT) alogorithm is required for maximum power extraction from the panel. There is a significant impact of environment on electrical characteristics of PV panel and MPP changes with a change in temperature and irradiation. PV module has a unique operating point $\left(\mathrm{I}_{\mathrm{mpp}}, \mathrm{V}_{\mathrm{mpp}}\right)$ where available power is maximum [4]-[8]. Maximum power extraction from the PV panel is achieved by connecting a converter to the PV system and controlling the voltage and current with MPPT algorithm to track the MPP at all operating condition. In PV 
power system, both PV panels and converters exhibit nonlinear and time-varying characteristics, which result in challenging control problem [9], [10].

The arithmetical model of a PV panel is vital to know which is coupled to a power converter in a PV system [11]. Unluckily all model parameters are not on hand in the data sheet provided by the manufacturer. Manufacturer datasheet only provide few parameters like open circuit voltage $\left(\mathrm{V}_{\mathrm{oc}, \mathrm{n}}\right)$, Short circuit current $\left(\mathrm{I}_{\mathrm{sc}, \mathrm{n}}\right)$, voltage and current at maximum power point $\left(\mathrm{V}_{\mathrm{mpp}, \mathrm{n}}, \mathrm{I}_{\mathrm{mpp}, \mathrm{n}}\right)$, temperature coefficients for voltage $\left(\mathrm{K}_{\mathrm{v}}\right)$, current $\left(\mathrm{K}_{\mathrm{I}}\right)$ and power $\left(\mathrm{K}_{\mathrm{p}}\right)$ at standard test condition $(\mathrm{STC})$. STC refers to irradiation of $1000 \mathrm{~W} / \mathrm{m}^{2}$ and temperature of $25^{\circ} \mathrm{C}$. Therefore it is essential to estimate unknown parameters to model a PV system accurately [12]. Different models of the PV module are classified as an ideal model, single diode four parameters model and single diode five parameters model [13]. The most commonly used model is the single diode five parameters model as shown in Figure 1. It has five unknown parameters as photogenerated current $\left(I_{p g}\right)$, saturation current $\left(I_{s}\right)$, diode quality factor $(a)$, series resistance $\left(R_{s e}\right)$ and shunt resistance $\left(R_{s h}\right)$. According to the semiconductor theory, diode $D$ represents the $p-n$ junction of the PV module and current $I_{d}$ stands for the escaping current through the $p-n$ junction due to the diffusion mechanism. Series resistance $\left(R_{\text {se }}\right)$ represents the losses due to contact resistance and shunt resistance $\left(R_{\text {sh }}\right)$ represents the leakage current at the p-n junction of the PV module. There are different parameter extraction techniques are available in literature with their merits and demerits [14]-[20]. In this paper, unknown parameters are estimated by nonlinear least square (NLS) technique and experimentally validated with a laboratory set up. The NLS technique is also compared with two known techniques such as Villalva's comprehensive technique and modified Newton-Raphson (N-R) technique [3], [21], [22]. The superiority of the proposed NLS technique is established by comparing the absolute error of maximum power.

\section{MODELLING OF PV PANEL}

The current voltage relationship of a PV panel is expressed as:[14]

$$
I_{p v}=I_{p g}-I_{s}\left[\exp \left(\frac{V_{p v}+R_{s e} I_{p v}}{N_{s} V_{t} a}\right)-1\right]-\frac{V_{p v}+R_{s e} I_{p v}}{R_{s h}}
$$

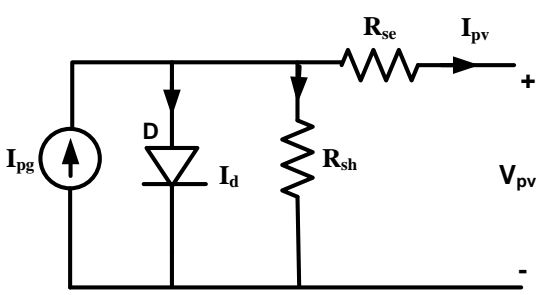

Figure 1.Popular $\mathrm{R}_{\mathrm{sh}}$ model of PV panel

$V_{p v}$ and $I_{p v}$ represent the module output voltage and current respectively, and $V_{t}$ is the thermal voltage of the p-n junction The electrical properties of the PV panel depend upon the environmental factor like solar insolation and temperature [23]. The dependency of photo-generated current and open-circuit voltage of the PV module is represented by equations:

$$
\begin{aligned}
& I_{p g}=\left[I_{p g, n}+K_{I} d t\right] \frac{G}{G_{n}} \\
& V_{o c}=V_{o c, n}+K_{v} d t
\end{aligned}
$$

Where, $\mathrm{I}_{\mathrm{pg}, \mathrm{n}}$ and $\mathrm{V}_{\mathrm{oc}, \mathrm{n}}$ are measured at a nominal condition of the temperature of $25^{\circ} \mathrm{C}$ and irradiation of $1000 \mathrm{~W} / \mathrm{m}^{2}$. The temperature difference $\left(\mathrm{dt}=\mathrm{T}-\mathrm{T}_{\mathrm{n}}\right)$ is a difference between nominal and actual temperature. $G$ is the insolation at operating condition, and $G_{n}$ is insolation at nominal condition. The saturation current of the PV module at a particular environmental condition is represented by equation (4) [3].

$$
I_{\mathrm{s}}=\frac{\mathrm{I}_{\mathrm{sc}, \mathrm{n}}+\mathrm{K}_{\mathrm{I}} \mathrm{dt}}{\exp \left(\frac{\mathrm{V}_{\mathrm{oc}, \mathrm{n}}+\mathrm{K}_{\mathrm{v}} \mathrm{dt}}{\mathrm{N}_{\mathrm{s}} \mathrm{V}_{\mathrm{t}} \mathrm{a}}\right)-1}
$$




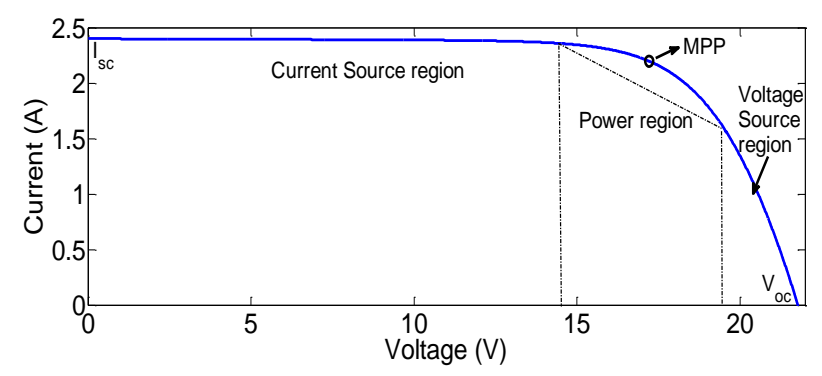

Figure 2. I-V curve of ELDORA-40 PV panel and its three remarkable points

The simulated current-voltage (I-V) characteristic of the test module at STC is shown if Figure 2 with its three remarkable points as $\mathrm{I}_{\mathrm{sc}}, \mathrm{V}_{\mathrm{oc}}$ and $\mathrm{P}_{\mathrm{mpp}}$. Power extraction from the PV panel will be maximum when the module is operated at its MPP.

\section{EXTRACTION OF PV MODULE PARAMETERS}

Construction of exact PV model is possible if all the electrical parameters of the module are to be extracted accurately. Here an attempt has been taken to extract the model parameters accurately using only the parameters of the manufacturer datasheet without any measurement. Three methods are discussed here with their merits and demerits.

\subsection{Starting of the methods}

To estimate five unknown parameters, five equations whose dependencies upon the unknown parameters is needed. Rewriting equation (1) at three remarkable points as short-circuit, open-circuit and MPP gives three equations as (5), (6) and (7) respectively [22].

$$
\begin{aligned}
& I_{s c}=I_{p g}-I_{s}\left[\exp \left(\frac{R_{s e} I_{s c}}{N_{s} V_{t} a}\right)-1\right]-\frac{R_{s e} I_{s c}}{R_{s h}} \\
& I_{p g}=I_{s}\left[\exp \left(\frac{V_{o c}}{N_{s} V_{t} a}\right)-1\right]+\frac{V_{o c}}{R_{s h}} \\
& I_{m p p}=I_{p g}-I_{s}\left[\exp \left(\frac{V_{m p p}+R_{s e} I_{m p p}}{N_{s} V_{t} a}\right)-1\right]-\frac{V_{m p p}+R_{s e} I_{m p p}}{R_{s h}}
\end{aligned}
$$

Two more equations are needed for solving five parameters model. Another two equations can be considered knowing the fact that $\frac{\mathrm{dP}}{\mathrm{dV}} \mid\left(\mathrm{V}=\mathrm{V}_{\mathrm{mpp}}\right)=0$ and $\frac{\mathrm{dI}}{\mathrm{dV}} \mid\left(\mathrm{I}=\mathrm{I}_{\mathrm{sc}}\right)=-\frac{1}{\mathrm{R}_{\mathrm{sh}}}$

$$
\begin{aligned}
& I_{m p p}=V_{m p p}\left[\frac{\frac{I_{s}}{N_{s} V_{t} a} \exp \left(\frac{V_{m p p}+R_{s e} I_{m p p}}{N_{s} V_{t} a}\right)+\frac{1}{R_{s h}}}{1+\frac{R_{s e} I_{s}}{N_{s} V_{t} a} \exp \left(\frac{V_{m p p}+R_{s e} I_{m p p}}{N_{s} V_{t} a}\right)+\frac{R_{s e}}{R_{s h}}}\right] \\
& \frac{1}{R_{s h}}=\frac{\frac{I_{s}}{N_{s} V_{t} a} \exp \left(\frac{R_{s e} I_{s c}}{N_{s} V_{t} a}\right)+\frac{1}{R_{s h}}}{1+\frac{R_{s e} I_{s}}{N_{s} V_{t} a} \exp \left(\frac{R_{s e} I_{s c}}{N_{s} V_{t} a}\right)+\frac{R_{s e}}{R_{s h}}}
\end{aligned}
$$


Some literature uses $\frac{\mathrm{dI}}{\mathrm{dV}} \mid\left(\mathrm{V}=\mathrm{V}_{\mathrm{oc}}\right)=-\frac{1}{\mathrm{R}_{\mathrm{se}}}$ as one equation but it has some disadvantages as discussed in

[24]. Now five equations are available to extract five unknown parameters using equations (5)-(9). Further improving the model the photo generated current may be written as equation (10) by neglecting saturation current $I_{s}$ in (5). $R_{\text {sh,min }}$ as given in equation (11) represents the minimum value of $R_{\text {sh }}$ taken as initial value of parallel resistance [3].

$$
\begin{aligned}
& I_{p g, n}=\frac{R_{s h}+R_{s e}}{R_{s h}} I_{s c, n} \\
& R_{\text {sh,min }}=\frac{V_{m p p}}{I_{s c}-I_{m p p}}-\frac{V_{o c}-V_{m p p}}{I_{m p p}}
\end{aligned}
$$

\subsection{Review of Villalva's iterative technique and mocified $N-R$ technique}

\subsubsection{Villalva's iterative technique}

This method intends to adjust $R_{s e}$ and $R_{s h}$ values such that with one pair of $\left\{R_{s e}, R_{s h}\right\}$, the maximum power as given in the datasheet $\left(\mathrm{P}_{\text {mpp,curve }}=\mathrm{V}_{\text {mpp }} * \mathrm{I}_{\mathrm{mpp}}\right)$ must be equal to $\mathrm{P}_{\text {mpp }}$, model. The iterative method

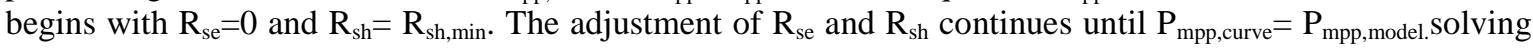
(12). Figure 3 represents the flow diagram of Villalva's technique. The main drawback of this technique is that the diode quality factor ' $a$ ' chosen arbitrarily between $1 \leq \mathrm{a} \leq 2$ before iteration starts. Only two parameters $R_{s e}$ and $R_{s h}$ are extracted by this method and $I_{p g}$ and $I_{s}$ values are calculated as per equation (2), (10) and (4). The extracted parameter values highly dependent on chosen tolerance and increment on $R_{\text {se }}$ value in the parameter extraction process.

$$
R_{\text {sh }}=V_{\text {mpp }}\left(V_{\text {mpp }}+R_{\text {se }} I_{m p p}\right) /\left\{V_{\text {mpp }} I_{p g}-V_{\text {mpp }} I_{s} \exp \left[\frac{V_{\text {mpp }}+R_{\text {se }} I_{m p p}}{N_{s} V_{t} a}\right]+V_{m p p} I_{s}-\text { P max, mod el }\right\}
$$

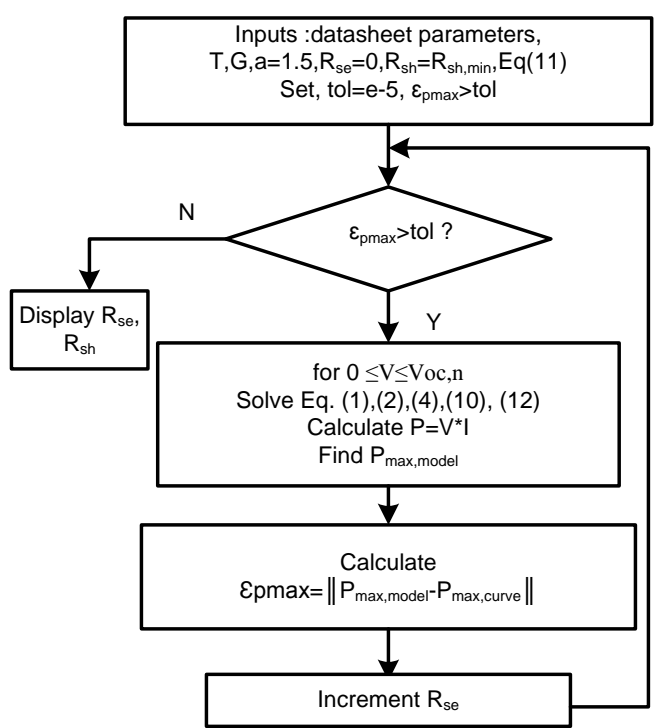

Figure 3. Flow diagram for Villalva's iterative method

\subsubsection{Modified N-R technique}

To mitigate slow convergence of N-R technique, the modified N-R technique has been developed to solve nonlinear equations with multiple roots. This technique is utilized for estimation of unknown 
parameters $X=\left[R_{s e}, R_{s h}\right.$, a. $\left.I_{p g}, I_{s}\right]$ by considering five nonlinear equations (5)-(9) using fsolve command in MATLAB. Chosen initial parameters play a vital role in accurate estimation of parameters.

\section{PROPOSED NLS TECHNIQUE}

\subsection{Starting of the technique}

To estimate unknown parameters of the polycrystalline Eldora-40 PV test module, equations (5)-(9) rewritten as [21].

$$
\begin{aligned}
& f_{1}(x)=0=\mathrm{I}_{\mathrm{pg}}-\mathrm{I}_{\mathrm{s}}\left[\exp \left(\frac{\mathrm{R}_{\mathrm{se}} \mathrm{I}_{\mathrm{sc}}}{\mathrm{N}_{\mathrm{s}} \mathrm{V}_{\mathrm{t}} \mathrm{a}}\right)-1\right]-\frac{\mathrm{R}_{\mathrm{se}} \mathrm{I}_{\mathrm{sc}}}{\mathrm{R}_{\mathrm{sh}}}-\mathrm{I}_{\mathrm{sc}} \\
& f_{2}(x)=0=\mathrm{I}_{\mathrm{s}}\left[\exp \left(\frac{\mathrm{V}_{\mathrm{oc}}}{\mathrm{N}_{\mathrm{s}} \mathrm{V}_{\mathrm{t}} \mathrm{a}}\right)-1\right]+\frac{\mathrm{V}_{\mathrm{oc}}}{\mathrm{R}_{\mathrm{sh}}}-\mathrm{I}_{\mathrm{pg}} \\
& f_{3}(x)=0=\mathrm{I}_{\mathrm{pg}}-\mathrm{I}_{\mathrm{s}}\left[\exp \left(\frac{\mathrm{V}_{\mathrm{mpp}}+\mathrm{R}_{\mathrm{se}} \mathrm{I}_{\mathrm{mpp}}}{\mathrm{N}_{\mathrm{s}} \mathrm{V}_{\mathrm{t}} \mathrm{a}}\right)-1\right]-\frac{\mathrm{V}_{\mathrm{mpp}}+\mathrm{R}_{\mathrm{se}} \mathrm{I}_{\mathrm{mpp}}}{\mathrm{R}_{\mathrm{sh}}}-\mathrm{I}_{\mathrm{mpp}} \\
& f_{4}(x)=0=\mathrm{V}_{\mathrm{mpp}}\left[\frac{\frac{\mathrm{I}_{\mathrm{s}}}{\mathrm{N}_{\mathrm{s}} \mathrm{aV}} \exp \left(\frac{\mathrm{V}_{\mathrm{mpp}}+\mathrm{R}_{\mathrm{se}} \mathrm{I}_{\mathrm{mpp}}}{\mathrm{N}_{\mathrm{s}} \mathrm{aV}}\right)+\frac{1}{\mathrm{R}_{\mathrm{th}}}}{1+\frac{\mathrm{R}_{\mathrm{se}} \mathrm{I}_{\mathrm{s}}}{\mathrm{N}_{\mathrm{s}} \mathrm{aV}_{\mathrm{t}}} \exp \left(\frac{\mathrm{V}_{\mathrm{mpp}}+\mathrm{R}_{\mathrm{se}} \mathrm{I}_{\mathrm{mpp}}}{\mathrm{N}_{\mathrm{s}} \mathrm{aV}}\right)+\frac{\mathrm{R}_{\mathrm{se}}}{\mathrm{R}_{\mathrm{sh}}}}\right]-\mathrm{I}_{\mathrm{mpp}} \\
& f_{5}(x)=0=\frac{\frac{\mathrm{I}_{\mathrm{s}}}{\mathrm{N}_{\mathrm{s}} \mathrm{aV}} \exp \left(\frac{\mathrm{R}_{\mathrm{se}} \mathrm{I}_{\mathrm{sc}}}{\mathrm{N}_{\mathrm{s}} \mathrm{V}_{\mathrm{t}} \mathrm{a}}\right)+\frac{1}{\mathrm{R}_{\mathrm{sh}}}}{1+\frac{\mathrm{R}_{\mathrm{se}} \mathrm{I}_{\mathrm{s}}}{\mathrm{N}_{\mathrm{s}} \mathrm{aV}} \exp \left(\frac{\mathrm{R}_{\mathrm{se}} \mathrm{I}_{\mathrm{sc}}}{\mathrm{N}_{\mathrm{s}} \mathrm{V}_{\mathrm{t}} \mathrm{a}}\right)+\frac{\mathrm{R}_{\mathrm{se}}}{\mathrm{R}_{\mathrm{sh}}}}-\frac{1}{\mathrm{R}_{\mathrm{sh}}}
\end{aligned}
$$

To reduce the computational complication and for reduction of iterations, NLS algorithm modifies multi-objective function to a single objective function. The initial parameter values, lower and upper limit constraints are chosen with its physical significance. The flow algorithm for NLS technique used for estimation of unknown parameters is shown in Figure 4. To solve five nonlinear equations by this approach, lsqnonlin command in MATLAB is used. The objective function $\mathrm{f}(\mathrm{x})$ is chosen as $\min _{x}(f(x))=f_{1}(x)^{2}+f_{2}(x)^{2}+f_{3}(x)^{2}+f_{4}(x)^{2}+f_{5}(x)^{2}$ considering upper and lower limit constraints.

\subsection{Initialization}

Since the accuracy of estimation depends very well upon the initial parameter values, an intelligent estimate of initial condition is very much essential for the solution to converge to the solution. From the available literature [3][25] the initial values of different parameters are as follows.

- $\mathrm{I}_{\mathrm{pg}}$ could be approximated by $\mathrm{I}_{\mathrm{sc}}$.

- $\mathrm{I}_{\mathrm{s}}$ is determined using equation (4).

- Quality factor ' $\mathrm{a}$ ' of the diode is chosen as $1 \leq \mathrm{a} \leq 2$.

- $\quad \mathrm{R}_{\mathrm{sh}}$ is a large value approximated according to (11).

- $\quad \mathrm{R}_{\mathrm{se}}$ is very small taken as 0 , or in the range of milliohms.

In most cases, convergence occurs with the aforementioned initialization. If it fails, initialization needs to be done randomly considering the range of each parameter values. The lower and upper bound of search must be chosen carefully, keeping in mind the minimum and maximum values of the parameters.

\section{RESULTS AND DISCUSSION}

Unknown parameters are estimated by NLS technique and obtained results are compared with two popular techniques like Villalva's comprehensive technique and modified N-R technique. Module 
characteristics are drawn at STC and compared as shown in Figure 5 and Figure 6. Extracted parameter values are validated by conducting experiment on ELDORA-40 PV panel. Figure 5 (a) shows the I-V characteristic of the ELDORA-40 PV panel and the result shows the characteristics match the datasheet remarkable points such as, $I_{\mathrm{sc}}, \mathrm{V}_{\mathrm{oc}}, \mathrm{V}_{\mathrm{mpp}}$, and $\mathrm{I}_{\mathrm{mpp}}$. Similarly Figure 5 (b) shows the P-V characteristics of the ELDORA-40 PV panel and result shows the good agreement between the datasheet curve and simulated curve using the extracted parameters. Table1 represents the datasheet of the test module at STC.

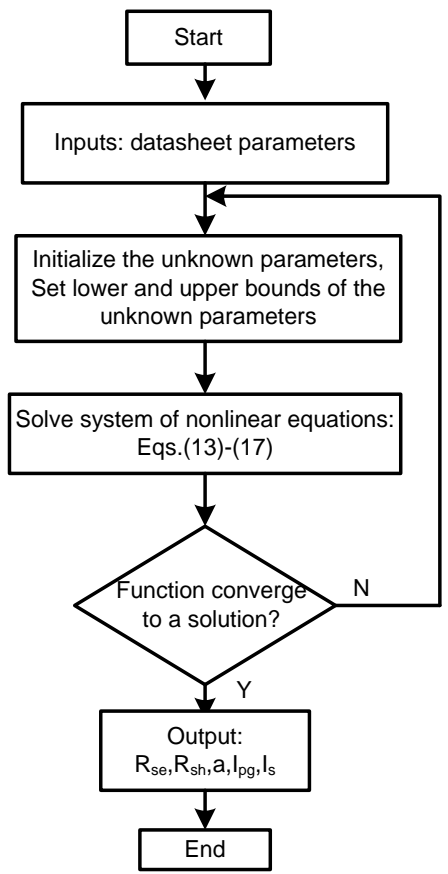

Figure 4. Fowchart for nonlinear least square method of parameter extraction

Table 1. Datasheet of the test module ELDORA-40 at STC

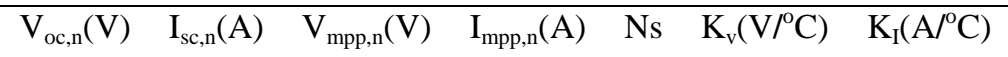

\begin{tabular}{lllllll}
\hline 21.8 & 2.4 & 17.2 & 2.20 & 36 & $-0.32 \%$ & $0.04 \%$ \\
\hline
\end{tabular}

Table 2. Comparison of extracted parameters of the test module at STC

\begin{tabular}{cccc}
\hline Parameters & $\begin{array}{c}\text { Villalva's technique } \\
\text { (Method-A) }\end{array}$ & $\begin{array}{c}\text { Modified N-R technique } \\
\text { (Method-B) }\end{array}$ & $\begin{array}{c}\text { NLS technique } \\
\text { (Method-C) }\end{array}$ \\
\hline $\mathrm{R}_{\mathrm{se}}(\Omega)$ & 0.493 & 0.53 & 0.58 \\
$\mathrm{R}_{\mathrm{sh}}(\Omega)$ & 939.35 & 466.31 & 704.24 \\
$\mathrm{a}$ & 1.5 (fixed) & 1.41 & 1.4 \\
$\mathrm{I}_{\mathrm{pg}}(\mathrm{A})$ & 2.4 & 2.402 & 2.4 \\
$\mathrm{I}_{\mathrm{s}}(\mathrm{A})$ & $3.62 \mathrm{e}-7$ & $1.1 \mathrm{e}-7$ & $1.1 \mathrm{e}-7$ \\
Time of computation $(\mathrm{S})$ & 3.8 & 1.2 & 0.34 \\
Absolute error of maximum power in $\%$ & 0.43 & 0.24 & 0.07 \\
\hline
\end{tabular}

The extracted parameter values are tabulated in Table 2 for ELDORA-40 PV module defined at STC. The extracted parameter values are compared and it is seen that parameter values are in good agreement with the datasheet characteristics. The absolute error of maximum power is calculated and seen that it is minimum for NLS technique. The time of computation for parameter extraction is less in NLS technique as compared to other two techniques. 


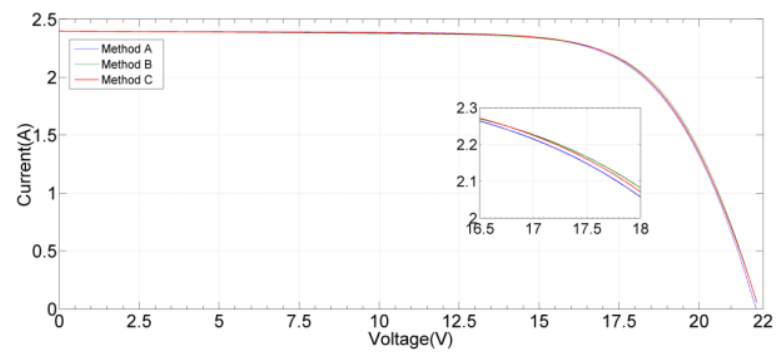

(a)

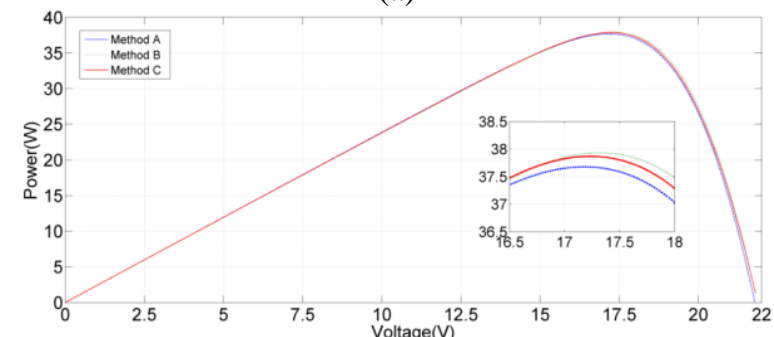

(b)

Figure 5. (a) I-V (b) P-V characteristic of the test module at STC

\subsection{Validation of the model}

To validate the extracted parameter values, the characteristic curve of ELDORA-40 PV panel has been drawn using the extracted parameter values. The test setup is placed inside the laboratory, and artificial irradiation is used with the help of halogen light as shown in Figure 6. The current and voltage values are measured from zero load to full load condition at $25^{\circ} \mathrm{C}$ of temperature and $220 \mathrm{~W} / \mathrm{m}^{2}$ of irradiation. Parameters extracted by NLS method has been used for simulation of the P-V and I-V curves of the PV panel at the above mentioned temperature and irradiation. Figure.7 (a) and Figure 7 (b) shows good agreement between the simulated and experimental characteristics, using the parameters extracted by the proposed NLS method. The absolute percentage error of maximum power is calculated and is found less than one percent. The I-V characteristic shown in Figure 7 (a) shows the simulated and experimental curve matching at almost all points including the three remarkable points. Similarly, P-V characteristics shown in Figure 7 (b) also show good agreement between simulated and experimental results.

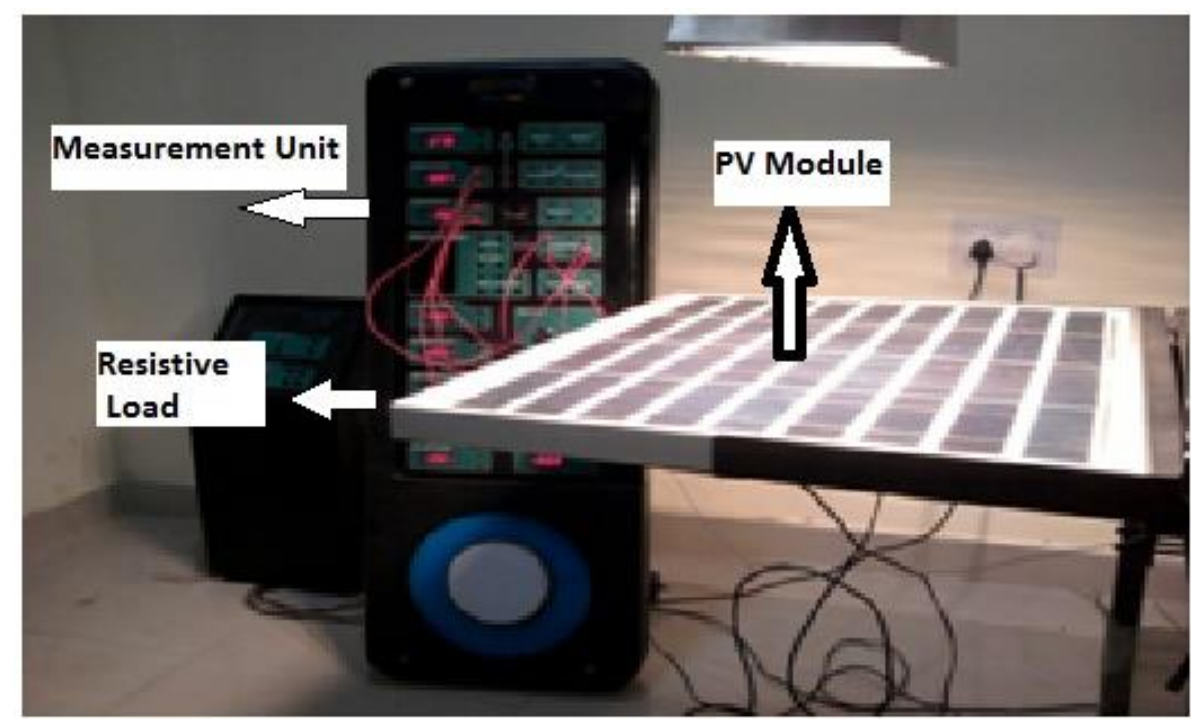

Figure 6. Test set-up of ELDORA-40 PV panel 


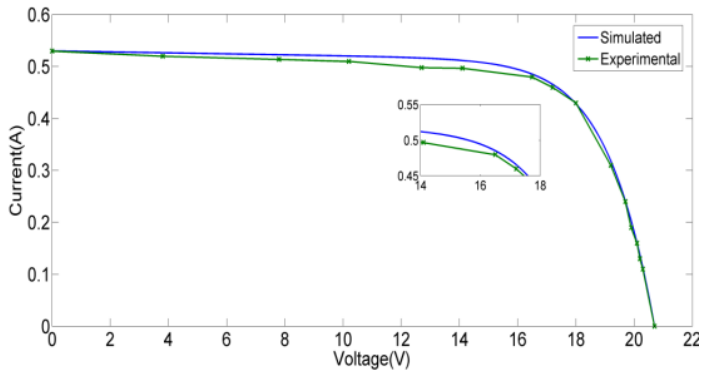

(a)

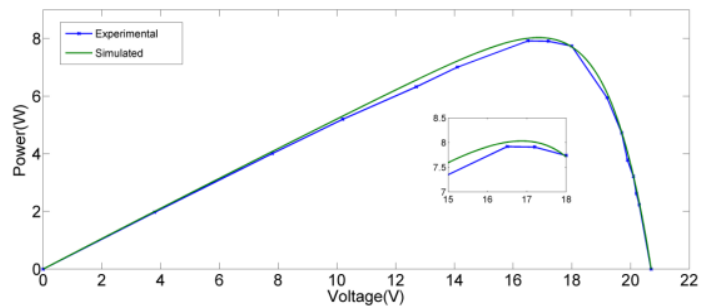

(b)

Figure 7. (a) I-V (b) P-V characteristic of the test module using the parameters extracted by NLS technique

\section{CONCLUSION}

In this paper, NLS technique is proposed for parameter extraction of PV module and is compared with other two well known techniques. All five unknown parameters of ELDORA-40 PV module extracted using three different techniques and compared. The characteristics of the PV module show that proposed NLS technique gives the best result with less computational complication compared to other two techniques. It is seen that the proposed technique not only give good results at STC but also at other temperature and irradiation. The absolute error of maximum power is compared with all the techniques and it is observed that the value is very less for NLS technique. The absolute error of maximum power is also calculated taking the experimental characteristics and simulated one at a temperature of $25^{\circ} \mathrm{C}$ and irradiation of $220 \mathrm{~W} / \mathrm{m}^{2}$ and it is found less than one percent. From the experimental results, it is observed that the unknown parameter extracted by the proposed NLS technique is correct and it validates the characteristic of the datasheet at all the three remarkable points with less error.

\section{REFERENCES}

[1] M. Taghi, S. Moslehpour, and M. Shamlo, "Economical load distribution in power networks that include hybrid solar power plants," Electr. Power Syst. Res., vol. 78, pp. 1147-1152, 2008.

[2] M. Louzazni, E. H. Aroudam, and H. Yatimi, "Modeling and Simulation of A Solar Power Source for a Clean Energy without Pollution,” Int. J. Electr. Comput. Eng., vol. 3, no. 4, pp. 568-576, 2013.

[3] M. G. Villalva, J. R. Gazoli, and E. R. Filho, "Comprehensive Approach to Modeling and Simulation of Photovoltaic Arrays,” IEEE Trans. Power Electron., vol. 24, no. 5, pp. 1198-1208, May 2009.

[4] A. Pallavee Bhatnagar and B. R. K. Nema, "Conventional and global maximum power point tracking techniques in photovoltaic applications: A review," Journal of Renewable and Sustainable Energy, vol. 5, no. 3. American Institute of PhysicsAIP, p. 32701, May-2013.

[5] T. Esram and P. L. Chapman, "Comparison of Photovoltaic Array Maximum Power Point Tracking Techniques,” IEEE Trans. Energy Convers., vol. 22, no. 2, pp. 439-449, 2007.

[6] A. Mohapatra, B. Nayak, and K. B. Mohanty, "Current based novel adaptive P\&O MPPT algorithm for photovoltaic system considering sudden change in the irradiance," in 2014 IEEE International Conference on Power Electronics, Drives and Energy Systems, PEDES 2014, 2014.

[7] A Jusoh, T Sutikno, TK Guan, S Mekhilef, "A Review on favourable maximum power point tracking systems in solar energy application," TELKOMNIKA Telecommunication Computing Electronics and Control., vol. 12, no. 1, pp. 6-22, 2014.

[8] K. T. Ahmed, M. Datta, and N. Mohammad, "A Novel Two Switch Non-inverting Buck-Boost Converter based Maximum Power Point Tracking System,” Int. J. Electr. Comput. Eng., vol. 3, no. 4, pp. 467-477, 2013. 
[9] W. Xiao, W. G. Dunford, P. R. Palmer, and A. Capel, "Regulation of photovoltaic voltage," IEEE Trans. Ind. Electron., vol. 54, no. 3, pp. 1365-1374, 2007.

[10] M. G. Villalva, T. G. de Siqueira, and E. Ruppert, "Voltage regulation of photovoltaic arrays: small-signal analysis and control design," IET Power Electron., vol. 3, no. 6, pp. 869-880, 2010.

[11] M. G. Villalva, J. R. Gazoli, and E. F. Ruppert, "Modeling and Circuit-Based Simulation of Photovoltaic Arrays," Brazilian J. Power Electron., vol. 14, no. 1, pp. 1244-1254, 2009.

[12] K. Azizi and A. Ghaffari, "Parameter estimation of photovoltaic panels and a model-based maximum power point tracking algorithm,” J. Renew. Sustain. Energy, vol. 8, no. 4, p. 43504, Jul. 2016.

[13] Y. Mahmoud, W. Xiao, and H. H. Zeineldin, "A Simple Approach to Modeling and Simulation of Photovoltaic Modules,” Sustain. Energy, IEEE Trans., vol. 3, no. 1, pp. 185-186, 2012.

[14] V. Chin, Z. Salam, and K. Ishaque, "Cell modelling and model parameters estimation techniques for photovoltaic simulator application: A review," Appl. Energy, vol. 154, pp. 500-519, 2015.

[15] Y. A. Mahmoud, W. Xiao, and H. H. Zeineldin, "A parameterization approach for enhancing PV model accuracy," IEEE Trans. Ind. Electron., vol. 60, no. 12, pp. 5708-5716, 2013.

[16] D. F. Alam, D. A. Yousri, and M. B. Eteiba, "Flower Pollination Algorithm based solar PV parameter estimation," Energy Convers. Manag., vol. 101, pp. 410-422, 2015.

[17] Y. Mahmoud and E. F. El-Saadany, "Fast power-peaks estimator for partially shaded PV systems," IEEE Trans. Energy Convers., vol. 31, no. 1, pp. 206-217, 2016.

[18] O. Hachana, K. E. Hemsas, G. M. Tina, and C. Ventura, "Comparison of different metaheuristic algorithms for parameter identification of photovoltaic cell/module," J. Renew. Sustain. Energy, vol. 5, no. 5, p. 53122, Sep. 2013.

[19] B. Subudhi and R. Pradhan, "A comparative study on solar array parameter extraction methods," Int. J. Renew. Energy Technol., vol. 3, no. 3, pp. 295-315, 2012.

[20] Y. Mahmoud and E. F. El-Saadany, "A Photovoltaic Model With Reduced Computational Time," IEEE Trans. Ind. Electron., vol. 62, no. 6, pp. 3534-3544, 2015.

[21] B. K. Nayak, A. Mohapatra, and K. B. Mohanty, "Parameters estimation of photovoltaic module using nonlinear least square algorithm: A comparative study," in 2013 Annual IEEE India Conference, INDICON 2013, 2013.

[22] D. Sera, R. Teodorescu, and P. Rodriguez, "PV panel model based on datasheet values," 2007 IEEE Int. Symp. Ind. Electron., pp. 2392-2396, Jun. 2007.

[23] G. Farivar and B. Asaei, "A new approach for solar module temperature estimation using the simple diode model,” IEEE Trans. Energy Convers., vol. 26, no. 4, pp. 1118-1126, 2011.

[24] B. Nayak, A. Mohapatra, and B. Misra, "Non Linear IV Curve Of PV Module: Impacts On MPPT And Parameters Estimation,” Int. J. Eng. Res. Technol., vol. 1, no. 8, pp. 1-8, 2012.

[25] A. Chatterjee, A. Keyhani, and D. Kapoor, "Identification of photovoltaic source models," IEEE Trans. Energy Convers., vol. 26, no. 3, pp. 883-889, Sep. 2011. 